\title{
Public Debt as a Burden on the Future Generation: A Keynesian Approach
}

\author{
Masayuki Otaki \\ The Institute of Social Sciences, The University of Tokyo, Tokyo, Japan \\ Email: ohtaki@iss.u-tokyo.ac.jp
}

Received 26 September 2015; accepted 23 October 2015; published 27 October 2015

Copyright () 2015 by author and Scientific Research Publishing Inc.

This work is licensed under the Creative Commons Attribution International License (CC BY).

http://creativecommons.org/licenses/by/4.0/

(c) (i)

\section{Abstract}

By using an overlapping generations (OLG) model in the context of the production economy, this paper shows that public debt lowers the future generation's well-being even in the situation of imperfect employment equilibrium. According to the dynamically extended multiplier theory, which has a rigorous microeconomic foundation, the effect of the redemption of public debt is equivalent to that of the balanced-budget multiplier because the redemption increases autonomous spending by old generation while the same amount of tax is levied on the young generation. Thus, the aggregate disposable income remains before the issuance since the value of the balanced-budget multiplier is unity. However, it is evident that real GDP before tax reduction increases; it costs more resources to earn the same disposable income. Therefore, it is unavoidable that the issuance of public debt impairs the welfare of future generation even in a Keynesian framework.

\section{Keywords}

Redemption of Public Debt, Burden on the Future Generation, Balanced-Budget Multiplier, Keynesian Economics, Fiscal Discipline

\section{Introduction}

Almost all advanced countries are concerned by the huge amounts of public debts carried over from the past. It seems to be unredeemable within a generation, and thus intergenerational conflicts in this regard are likely to become increasing. However, besides the seminal work of Diamond [1], who shows that the segregated sequence of intergenerational economic decisions ends in market failure (i.e. dynamic inefficiency) and that the issuance of public debt prevents the sufficient capital accumulation, other famous studies are rather optimistic about the redemption of public debt despite the aforementioned grievous fact.

Ricardo [2] is an exception. He argues that since the issuance of public debt implies the same amount of fu- 
ture tax liability, it only results in income transfer from the taxpayers to those who are exonerated from taxation (most of whom are debt holders). He warns that this is, therefore, prone to impair the cohesion of the society. In addition, since the levied tax calls for the same amount of savings, government expenditure financed by such tax is entirely cancelled out by the savings, and hence income does not increase by the issuance of public debt. ${ }^{1}$ One must note that Ricardo is acutely aware of the devastating nature of the conflict between tax payers and recipients, even though such an income transfer is implicitly assumed to belong to the same generation.

Lerner [3] radically alleges that there is no future burden accrued from the issuance because the redemption is only a kind of transfer within a country. Ricardo and Lerner offer the same argument in the sense that tax associated with the redemption is a transfer within the same nation as far as public debt is not external but internal although Lerner seems too optimistic about levying tax ${ }^{2}$. This comes from his emphasis on the role of "functional finance", which is nowadays called the aggregate demand management policy. One of important aims of this study is to examine his assertion critically; that is, whether public debt becomes a burden to future generation when an economy is entrapped by imperfect employment equilibrium.

As a case for the redemption and taxation across generations, Barro [4] suggests that if each generation is altruistic to only their subsequent generation, it maximizes the utility by integrating its own budget constraint and its descendant. Accordingly, he asserts that the monetary gain from the issuance of public debt is entirely canceled out by the corresponding future tax liability. Thus, the Ricardian equivalence theorem, in the narrow sense that public debt does not comprise the net wealth in an economy as a whole, can be extended by adopting the local altruism.

Nonetheless, if such altruism were prevalent, there would be no serious intergenerational conflict as we observe presently. This paper examines how the issuance and redemption of public debt affect the intergenerational resource allocation and income distribution in a monetary economy by using a dynamically extended multiplier theory developed by Otaki [5]-[7].

This theory is characterized by the property that the equilibrium price level sequence is unrelated to the nominal money supply. This property is vital for negating the quantity theory of money as in Lucas [8].

Money can function as a store of value because everyone is confident that money is the only transaction medium and vice versa, and hence both functions are inseparable as ([7], Ch.14) exactly proves. This fact acutely suggests that current value (the inverse of the price level) of money crucially depends on its future value without conferring the condition of nominal supply. Accordingly, as far as the rational expectation on the future value of money is stable, current price level becomes endogenously fixed and independent of the level of aggregate demand. This property of the theory immediately implies that, without unprecise and arbitrary assumption of menu cost (or staggered pricing rule) associated with the utility function which contains the real cash balance, one can describe the state of imperfect employment as an Pareto-inferior equilibrium. This theory also derives Keynes's investment multiplier when the lifetime utility function from consumption is homothetic and additively separable from the disutility of labor.

Based on this theory, this paper analyzes how the issuance and redemption affect the related generational well-being. Whenever the government expenditure, which is financed by public debt, increases, the disposable income of the current generation also increases (although the value of the multipliers differ depending on whether or not the expenditure is directly transferred to individuals), and heightens its economic welfare under some weak condition.

\footnotetext{
${ }^{1}$ According to ([2], Ch.17]), "But independently of his consideration, it is by no means certain, that political utility would gain any thing by the sacrifice of political integrity; it does by no means follow, that the party exonerated from the payment of the interest of the national debt would employ it more productively than those to whom indisputably it is due. By cancelling the national debt, one man's income might be raised from $£ 1000$ to $£ 1500$. But another man’s would be lowered from $£ 1500$ to $£ 1000$. These two men’s incomes now amount to $£ 2500$. They would amount to no more than then. If it be the object of Government to raise tax, these would be precisely the same taxable capital and income in one case, as in the other. It is not, then, by the payment of the interest rate on the national debt, that a country is distressed, nor is it by the exoneration from payment that it can be relieved. It is only by saving from income, and retrenching in expenditure, that the expenditure diminished by the annihilation of the national debt. It is by the profuse expenditure of Government, and of individuals, and by loans, that the country is impoverished; every measure, therefore, which is calculated to promote public and private economy, will relieve the public distress: but it is error and delusion to suppose, that a real national economy difficulty can be removed, by shifting it from the shoulders of one class of the community, who justly ought to bear it, to shoulders of another class, who, upon principle equity, ought bear no more than their share".

${ }^{2}$ According to ([3], p. 303), "the national debt is not a burden on posterity because if posterity pays the debt it will be paying it to the same posterity that will be alive at the time when the payment is made. The national debt is not a burden on the nation because every cent in interest or repayment that is collected from the citizens as taxpayers to meet the debt service is received by the citizens as government bondholders".
} 
Nevertheless, the true problem is not located there. The effect of the redemption of such public debts to the subsequent generation is problematic. This generation is levied by the same amount as the sum of principal and interest of the issued public debt. In another aspect, however, the old generation, which enjoys much consumption during the previous period, holds much money because of the redemption. This stimulates the aggregate consumption. Consequently, one will find that the macroeconomic effect of the redemption is represented by the balanced-budget multiplier, the value of which is unity. Hence, the disposable income of the subsequent generation is kept at the same level as that of the preceding generation in the issuance of public debt.

It must be noted, however, that keeping the disposable income unchanged never means that economic welfare is not affected by the redemption. This is because more resources are demanded for the redemption despite the invariant disposable income. Thus, it is evident that redemption aggravates the welfare of the subsequent generation. In this sense, the issuance of public debt becomes a future burden.

This paper is organized as follows. Section 2 constructs the model and shows the results of the comparative statics concerning the issuance and redemption of public debt. It is also considered why fiscal discipline is prone to be dysfunctional in Section 3, based on the model in Section 2. Section 4 provides the brief concluding remarks.

\section{The Model and the Seriousness of the Problem}

\subsection{The Model}

This paper assumes a two-period overlapping generations (OLG) model with an infinite time horizon where output markets are under monopolistic competition. This model is developed by [5] [6] and generalized by [7]. There are non-atomistic firms that monopolistically produce differentiated goods in the density of points located within the interval $[0,1]$. Let the character of a firm be denoted $\omega$. The only production resource is labor, and for simplicity, unit labor produces unit differentiated goods. Each firm $\omega$ can employ its attached individuals, whose density is also located within $[0,1]$. That is, individuals totally exist in the density of the interior points of the square $[0,1] \times[0,1]$.

Each individual possesses the same utility function, $U$,

$$
U_{t} \equiv u\left(c_{1 t}, c_{2 t+1}\right)-\delta_{t} \cdot \alpha, \quad c_{k l} \equiv\left[\int_{0}^{1}\left[c_{k l}(\omega)\right]^{1-\eta^{-1}} \mathrm{~d} \omega\right]^{\frac{1}{1-\eta^{-1}}}, \quad \eta>1,
$$

where $u$ is a concave and homothetic function. $\alpha$ denotes the disutility of labor. $\delta_{t}$ is a definition function, which takes value unity when employed and zero when unemployed.

There are two kinds of store of value in this economy. One is money. The other is public debt. The public debt accrues units of money at gross interest rate $\theta$, which is set at the government discretion. Accordingly every individual wishes to save his or her income in terms of the public debt because there is no uncertainty. For clarifying the role of the public debt, it is dared to assume that the supply of the public debt is too scarce to satisfy the whole demand for saving. One must note that this analysis never loses generality even though the interest is attached to all money as [8] assumes. In addition, it is assumed that tax is levied only on firms.

The maximization of lifetime consumption leads us to the following indirect utility function concerning consumption and the corresponding price index:

$$
h_{t} \equiv f\left(\frac{y_{t}^{d}}{\varphi\left(\pi_{t}\right)}\right), \quad P_{t} \equiv\left[\int_{0}^{1}\left[p_{t}(\omega)\right]^{1-\eta} \mathrm{d} \omega\right]^{\frac{1}{1-\eta}}, \pi_{t} \equiv \frac{P_{t+1}}{P_{t}},
$$

where $y_{t}^{d}$ is the real disposable income in terms of current goods. $f$ is a monotonously increasing and invertible function. In accordance with [5], it is assumed that the labor markets are in interior equilibrium (i.e. there is imperfect employment equilibrium) and the equilibrium nominal wage stacks at the nominal reservation wage. Equations (1) and (2) give the nominal equilibrium wage, $W_{t}$, as

$$
W_{t}=P_{t} \varphi\left(\pi_{t}\right) \cdot f^{-1}(\alpha) .
$$

Here it is assumed that the concept of goods markets is a symmetric Nash equilibrium, and hence obtains the following optimal pricing rule: 


$$
\begin{aligned}
& P_{t}=\frac{W_{t}}{1-\eta^{-1}}=\frac{P_{t} \varphi\left(\pi_{t}\right) \cdot f^{-1}(\alpha)}{1-\eta^{-1}} \\
& \Leftrightarrow \varphi\left(\pi_{t}\right)=\frac{\left[1-\eta^{-1}\right]}{f^{-1}(\alpha)} \equiv \varphi\left(\pi^{*}\right) .
\end{aligned}
$$

Thus, the equilibrium inflation rate becomes constant over time. In addition, by applying Roy's identity to Equation (2), one obtains the aggregate consumption function, $C_{t}$, as

$$
C_{t}=c\left(\pi^{*}\right) y_{t}^{d},
$$

where $y_{t}^{d}$ is the aggregate real disposable income evaluated at the current price level. ${ }^{3}$

For closing the model, one needs to specify the money-supply rule, or equivalently, the budget constraint of the government. To purify the effect of issuance and redemption of public debt, one must eliminate the effect of changes in the real cash balance owing to inflation. Accordingly, one obtains the following budget constraint of the government:

$$
\frac{M_{t}-M_{t-1}}{P_{t}}=g \Rightarrow\left[1-\frac{1}{\pi^{*}}\right] m=g, m=\frac{M_{t}}{P_{t}}=\frac{M_{t-1}}{P_{t-1}},
$$

where $g$ denotes the real government expenditure towards some wasteful objects. $m$ is the real cash which is assumed to be constant over time.

Let the time schedule of public debt management be specified to elucidate the effects to the economy and its welfare implications. At period $t-1$, there is no asset other than money. This period becomes the reference point of the comparison. During period $t$, public debts are newly issued the nominal sum of which amounts to $D$. The corresponding revenue is entirely transferred to the individuals who are born during the previous period $t-1$. Such debts expire at the beginning of period $t+1$, and I assume that no rollover is possible. The necessary nominal tax, $D$, is young generation's due.

As such, the equilibrium condition of the aggregate goods market and equilibrium real GDP is classified into the following three cases:

Case 1: Period $t-1$

$$
\begin{aligned}
& y_{t-1}=c\left(\pi^{*}\right) y_{t-1}+g+\frac{M_{t-1}}{P_{t}}=c\left(\pi^{*}\right) y_{t-1}+m \\
& \Rightarrow y_{t-1}=y_{t}^{d}=\frac{m}{1-c\left(\pi^{*}\right)},
\end{aligned}
$$

where the third term on the right-hand side at the beginning of Equation (7) denotes the consumption of the old generation. When one takes the government's budget constraint, Equation (6), into consideration, the final form of Equation (7) is obtained.

\section{Case 2: Period $t$}

$$
\begin{aligned}
& y_{t}=c\left(\pi^{*}\right)\left[y_{t}+[\theta-1] \cdot \frac{D}{P_{t}}\right]+m+\frac{D}{P_{t}} \\
& \Rightarrow y_{t}=\frac{\left[1+c\left(\pi^{*}\right) \cdot[\theta-1]\right] \cdot \frac{D}{P_{t}}+m}{1-c\left(\pi^{*}\right)} \Rightarrow y_{t}^{d}=\frac{\theta \cdot \frac{D}{P_{t}}+m}{1-c\left(\pi^{*}\right)} .
\end{aligned}
$$

The terms inside of the square bracket on the right-hand side on the top of Equation (8) are the real aggregate disposable income in terms of current goods. $[\theta-1] \cdot \frac{D}{P_{t}}$ corresponds to the income accrued from the interest on the public debt. The third term represents the transfer to the old generation financed by the public debt.

\footnotetext{
${ }^{3}$ Note that the opportunity cost for current consumption is not the real rate of interest but the inflation rate because this study assumes that the equilibrium effective demand is sufficiently high so that the aggregating exceeds the issued public debt.
} 
Case 3: Period $t+1$

$$
\begin{aligned}
& y_{t+1}=c\left(\pi^{*}\right)\left[y_{t+1}-\frac{\theta}{P_{t+1}} \cdot D\right]+m+\frac{\theta}{P_{t+1}} \cdot D \\
& \Rightarrow y_{t+1}=\frac{m}{1-c\left(\pi^{*}\right)}+\frac{\theta}{P_{t+1}} \cdot D \Rightarrow y_{t+1}^{d}=\frac{m}{1-c\left(\pi^{*}\right)} .
\end{aligned}
$$

The term of the inside of the square bracket at the beginning of Equation (9) expresses the real disposable income of the young generation since tax is levied on the young generation to redeem the public debt issued in the previous period. The third term on the right-hand side of this equation refers to the real expenditure of the old generation, who were born at the beginning of period $t$, from the redemption.

The obtained result is summarized in Figure 1. There are two important facts. First, as the figure indicates, the real disposable income is unchanged before and after the issuance of the public debt, and the real disposable income increases only during the period (period $t$ ) in which the issuance occurs. Second, the issuance of the public debt is beneficial for both for the old and young generations who live during the corresponding period. This fact implies that every period offers the incentive for enriching the economy via fiscal deficit. As discussed in the next section, this is quite a precarious propensity when one assigns much importance to sustainability (or the well-being of the residents of the economy over time).

Finally, let implications of welfare economics on the issuance of public debt be analyzed, that is, whether public debt becomes a burden to future generation. To clarify the analysis one needs define what constitutes a "burden on the future generation". That is,

\section{Definition 1}

This study posits that the issuance of public debt becomes a burden on the future generation whenever such issuance lowers the welfare of the subsequent generation compared with that of the generation living in the advent of the issuance.

As par the above definition, one should compare the economic welfare of the generation born at the beginning of period $t+1$ (the $t+1$ th generation) with that of the $t-1$ th generation. One finds that both generations achieve the same level of the real disposable income (i.e., $\left.\frac{m}{1-c\left(\pi^{*}\right)}\right)$. This is because the economic environment surrounding the $t+1$ th generation coincides with the implementation of the additional balanced-budget expansionary fiscal policy at period $t-1$. That is, the increase in the consumption of the old generation associated with the redemption of the public debt incurs the same amount of taxation from the young generation at period $t+1$.

Nonetheless, this does not imply that the economic welfare, which each generation enjoys, remains unchanged by the issuance of public debt at period $t$. This is because higher GDP is required for the $t+1$ th generation to achieve the same disposable income. The fact that higher GDP is necessary means that the $t+1$ th generation uses more input to obtain the same well-being as the $t-1$ th generation. Accordingly, from Definition 1, it is clear that the issuance of public debt is surely a burden on the future generation. More rigorously, one can prove the following theorem:

\section{Theorem 1}

The issuance of the public debt at period t becomes a burden on the future generation in the sense of Definition 1.

Proof

Since the equilibrium nominal wage stacks to the nominal reservation wage, a worker's utility never changes in conjunction with the employment level. Accordingly, from the property of the lifetime indirect utility function (2), one can focus on the change of firm's profit to prove the theorem. From the optimal pricing rule (4) and the symmetry of goods markets equilibrium, the net profit after the deduction of tax for the redemption, $S U R_{t+1}$, which is equal to the total economic surplus of generation $t+1$, is

$$
S U R_{t+1} \equiv \eta^{-1} y_{t+1}-T \text {. }
$$

As is clear from Equations (7) and (9), the economic circumstance of period $t+1$ is equivalent to that in pe- 


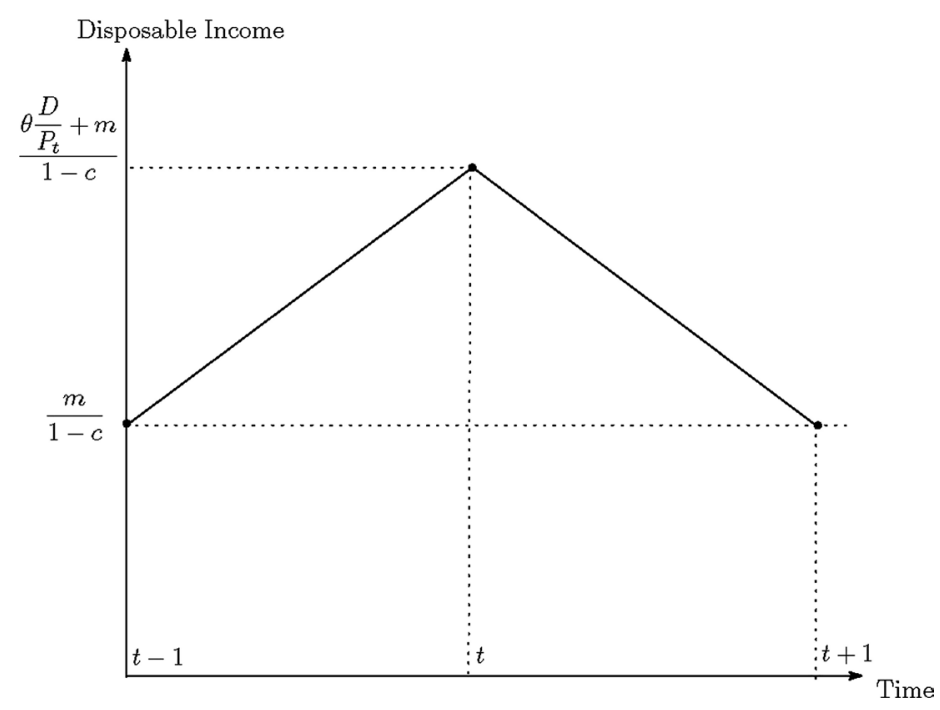

Figure 1. Public debt and disposable income.

riod $t-1$ plus the balanced-budget fiscal expansion which amounts to $\frac{\theta}{P_{t+1}} \cdot D$. Since the value of the balanced-budget multiplier is unity, by differentiating Equation (10), I obtain

$$
\mathrm{d} S U R_{t+1} \equiv\left[\eta^{-1}-1\right] \mathrm{d} T<0 .
$$

Equation (11) completes the proof.

\subsection{The Seriousness of the Problem in Japan}

Using the formula of (11) and data in SNA statistics in Japan, let how the welfare is reduce by the minimum redemption be estimated although it remains tentative and belongs to an estimation based on round numbers.

Since the accumulated stock of public debt in Japan soars up about 1300 trillion yen at 2015 and its population is about 0.13 billion, the hoarded public debt is about 10 million yen per capita. Although such an enormous accumulation has reached precarious point, let this level be regarded as the highest sustainable limit and assume that the Japanese government strives to keep this critical level with issuing 20 trillion yen fiscal deficit per annum (admittedly, it is far from reality).

The reduction of population in Japanese society is a key role. According to the statistics provided by National Institute of Population and Social Security Research, the population of Japan will decrease about 40 million by 2050. Accordingly, to keep the critical level (i.e., 10 million yen per capita), 400 trillion yen of the public debt should be redeemed from the currently existing debt. This implies, even though one neglects the interest payments, that the government must begin to correct additional tax, which amounts about 12 trillion yen per year immediately.

Since $1-\eta^{-1}$ corresponds to the share of total labor income, Japanese SNA statics says, it is located around 70 per cent. Thus, from the formula (11), the loss of welfare in terms of money is estimated as

$$
0.7 \times[20+12]=22.4 \text { (trillion yen/year). }
$$

Such a figure amounts about 5 percent of current annual GDP of Japan. This estimation is, however, based on unimaginably optimistic assumptions. Hence, some caveats should be added. First, the population reduction brings about a more serious effect to Japanese economy because it is associated with the rapid aging. This implies that the potential production capacity will be surely curtailed and thus thwarts the aggregate saving, which is the very fund for financing the public debt. Second, also relating to the aging, as current SNA statistics evidently shows, one of the most serious concerns about the fiscal deficit is the hike of the social security expenditure, the constituents of which are mostly public pension fund and medical care. Such expenditures will never decrease even though increase in conjunction with the aging. 


\section{The Importance of Fiscal Discipline}

The discussion in the previous section reveals following two precarious properties of the issuance of public debt.

1) Despite the unavoidableness of redemption, every two succeeding generations have a propensity to issue public debt because such a deed enriches them both.

2) As Theorem 1 asserts, since the redemption of public debt necessarily aggravates the well-being of the young generation at that time, it is likely to be postponed as far as possible.

As such, once people experience the ephemeral pleasure obtained by fiscal deficit, there is an appalling tendency that the issuance of public debt ceaselessly continues until the government declares the (at least partial) default of its debt. The enforcement of fiscal discipline is, therefore, urgently required.

One might argue that autonomous expansion of outstanding public debt associated with increases in interest payment will automatically lead to full-employment equilibrium. However, it must to be noted that the stock of public debt exploded with such an irresponsible debt-management policy, which sets no limit. Accordingly, such an economy is forced to declare the default sooner or later, and thus the interest must be paid to the debt holders by levying the tax to preserve the stock of public debt (i.e., maintain it at a constant level) over time and make the economy sustainable.

Let the sustainable real public debt be denoted as $\bar{d}\left(\bar{d} \equiv \frac{D_{t+j}}{P_{t+j+1}}\right) \cdot \bar{d}$ satisfies

$$
\begin{gathered}
1-c\left(\pi^{*}\right)\left[1-\pi^{*}[\theta-1] \cdot \bar{d}\right]=m+\pi^{*} \theta \cdot \bar{d} \\
\Rightarrow \bar{d}=\frac{1-\frac{m}{1-c\left(\pi^{*}\right)}}{\theta+\frac{c\left(\pi^{*}\right)}{1-c\left(\pi^{*}\right)}} \cdot \frac{1}{\pi^{*}} .
\end{gathered}
$$

From Equation (10), it is apparent that whenever the total social surplus, SUR, is negative, and the taxation for collecting the interest payment exceeds the benefit, which stems from achieving full employment, full employment is unattainable. Accordingly, if

$$
\pi^{*}[\theta-1] \cdot \bar{d}>\eta^{-1}
$$

holds, an irresponsible pubic-debt management policy, which satisfies properties 1) and 2), triggers the default sooner or later. It is evident that an extremely low interest policy (including a zero-interest policy), which sets $\theta$ close to unity, is inevitable for avoiding the default as the experiences of the world economy show. The default of public debt denotes income redistribution at the government's discretion between the unfortunate generations, the occurrence of which [2] acutely warns us against.

Nevertheless, one must note that this paper neglects alternative investment opportunities such as real capital the rate of return of which is thought to be significantly positive. In such a case, the nominal rate of interest $\theta$ is not dependent on the government's discretion, and thus, a zero-interest policy is no longer feasible at least in the long run. Consequently, one might experience much difficulty in mitigating a crisis caused by default of public debt. That is, fiscal discipline is the bedrock of sustaining a sound monetary economy in reality.

\section{Concluding Remarks}

This study considers whether public debt becomes a burden on the future generation mainly under imperfect employment equilibrium. The results indicate the followings.

First, the issuance of public debt becomes a burden on the future generation because more taxes are necessary to regain the same disposable income earned at the advent of the issuance. Second, unlike [4] altruistic assumption, if the concern of an individual is confined to his or her own well-being, every two succeeding generations are likely to prefer issuing public debt. This fact owes much to the propensity, that is, the old generation in question can enjoy affluent consumption financed by the public debt, and at the same time, the young generation that coexists is also enriched because the aggregate demand is stimulated by the increased expenditure of the old generation. One must note that this is quite a precarious tendency because such ephemeral prosperity postpones 
the redemption of public debt as far as possible, and, far worse, accelerates the accumulation of debt.

Finally, one might assert that the state of full employment hinders such a worrisome propensity. However, as the equations in Section 3 reveal, unless propensity to save or the degree of monopoly (the inverse of the elasticity of demand to its relative price), which is the very origin of the social surplus of the young generation in this model, ${ }^{4}$ is sufficiently high, the default of public debt is hardly avoidable by the achievement of full employment. This assertion implies that a partial default of public debt, which is equivalent to an income readjustment by the monetary authority between the old and young generations living during the period in question, is unavoidable.

The author must mention that the model neglects the effect of capital accumulation, which enriches the aggregate saving. Taking such a factor into consideration would require a more precise analysis of the public-debt crisis.

\section{References}

[1] Diamond, P.A. (1965) National Debt in a Neoclassical Growth Model. American Economic Review, 60, $1126-1150$.

[2] Ricard, D. (1821) On the Principles of Political Economy and Taxation. 3rd Edition. http://www.econlib.org/library/Ricardo/ricP4.html\#17.4

[3] Lerner, A.P. (1944) The Economics of Control: Principles of Welfare Economics. Macmillan, London.

[4] Barro, R.J. (1974) Are Government Bonds Net Wealth? Journal of Political Economy, 82, 1095-1117. http://dx.doi.org/10.1086/260266

[5] Otaki, M. (2007) The Dynamically Extended Keynesian Cross and the Welfare-Improving Fiscal Policy. Economics Letters, 96, 23-29. http://dx.doi.org/10.1016/j.econlet.2006.12.005

[6] Otaki, M. (2009) A Welfare Economics Foundation for the Full-Employment Policy. Economics Letters, 102, 1-3. http://dx.doi.org/10.1016/j.econlet.2008.08.003

[7] Otaki, M. (2015) Keynesian Economics and Price Theory: Re-Orientation of a Theory of Monetary Economy. Springer-Japan, Tokyo. http://dx.doi.org/10.1007/978-4-431-55345-8

[8] Lucas Jr., R.E. (1972) Expectations and the Neutrality of Money. Journal of Economic Theory, 4, 103-124. http://dx.doi.org/10.1016/0022-0531(72)90142-1 